Original Article

\title{
The effects of central post-stroke pain on quality of life and depression in patients with stroke
}

\author{
Şule Şahin-Onat, MD ${ }^{1)^{*}}$, Sibel Ünsal-Delialioğlu, MD ${ }^{1)}$, Fazil Kulakli, MD ${ }^{1)}$, \\ SuMru ÖZEL, MD ${ }^{1)}$ \\ 1) Department of Physical and Rehabilitation Medicine, Ankara Physical and Rehabilitation Medicine \\ Training and Research Center: Türkocă̆ street. No:3 Sihhiye 06230, Ankara, Turkey
}

\begin{abstract}
Purpose] The aim of this study was to assess the effects of central poststroke pain on quality of life, functionality, and depression in stroke. [Subjects and Methods] Twenty-four patients with stroke having central poststroke pain (a mean age of $60.6 \pm 8.5$ years; 14 males, 10 females; Group I) and 24 similar age-and gendermatched patients with stroke without central poststroke pain (Group II) were enrolled. Characteristics of pain were recorded in patients with stroke having central poststroke pain. The Visual Analogue Scale and Leeds Assessment of Neuropathic Symptoms and Signs pain scale were used to evaluate pain. The Functional Independence Measure was used to assess functionality, the 36-Item Short-Form Health Survey was used to assess quality of life (QoL), and the Beck Depression Inventory was used to assess depression. [Results] There were no significant differences in Functional Independence Measure and Beck Depression Inventory. Some of the 36-Item Short-Form Health Survey domains (physical role limitations, pain, and physical scores) in Group II were significantly higher than those in Group I. Additionally, we found that a unit increase in Leeds Assessment of Neuropathic Symptoms and Signs score led to 0.679 decrease in physical score and 0.387 decrease in mental score. [Conclusion] The physical component of the 36-Item Short-Form Health Survey is negatively affected in patient with central poststroke pain, but the mood and mental components of the scale unaffected.

Key words: Pain, Quality of life, Stroke
\end{abstract}

(This article was submitted Sep. 16, 2015, and was accepted Oct. 9, 2015)

\section{INTRODUCTION}

Central poststroke pain (CPSP) is characterized by pain and sensory abnormalities in the body (when other causes of obvious nociceptive, psychogenic, or peripheral pain have been excluded) after cerebrovascular lesion of the somatosensory system $^{1,2)}$. The prevalence of CPSP has been reported to be $7.3 \%{ }^{2,3)}$. By a year after stroke onset, quality of life $(\mathrm{QoL})$ decreases $40 \%$ compared with before a stroke ${ }^{4}$. As pain is known to affect recreational activities, vocational status, and quality of sleep, it can have a major role on QoL, mood, and rehabilitation outcome ${ }^{5-7}$. For many of patients with CSPS, the pain is severe and accompanied by reduced physical functioning, eventually lowering the $\mathrm{QoL}^{8}{ }^{89}$. Further, pain and psychological disorders are closely related, affecting physical and psychosocial functioning ${ }^{10,11)}$. Likewise, CPSP has an important effect on QoL, and a strong relationship has been observed between pain and depression ${ }^{5)}$.

Although CPSP can be expected to have a negative impact on QoL and mood in patients with stroke, to the best of our knowledge, no controlled study has been performed in this regard. Accordingly, the aim of this study was to assess the effects of CPSP on QoL and mood in patients with stroke and to determine the characteristics of CPSP. It was our hope that this study would encourage clinicians to may more attention to CSPS in patient with stroke.

\footnotetext{
*Corresponding author. Şule Şahin-Onat (sahinsuester@gmail.com)

(C)2016 The Society of Physical Therapy Science. Published by IPEC Inc.

This is an open-access article distributed under the terms of the Creative Commons Attribution Non-Commercial No Derivatives (by-nc-nd) License $<$ http://creativecommons.org/licenses/by-nc-nd/3.0/>.
} 


\section{SUBJECTS AND METHODS}

Twenty-four patients with CPSP (a mean age of 60.6 $\$ 8.5$ years; 14 males, 10 females; Group I) and 24 similar age-and gender-matched patients with stroke without CPSP (Group II) were enrolled. All patients who underwent inpatient rehabilitation treatment at Ankara Physical Medicine and Rehabilitation Education and Research Center were examined between January 2013 and February 2014. The patients included in the study were able to speak and understand the tests, and had stroke with a duration of at least one month. Patients were excluded from the study if they were not unconscious or had nociceptive or neuropathic pain due to other causes (i.e., complex regional pain syndrome, shoulder problems, brachial plexus injuries). All patients signed an informed consent form, and the study protocol was approved by the local ethical committee.

Demographic characteristics (age, gender, marital status, educational level); duration, type, side of stroke; dominant hemisphere; and medical history were recorded. Lesion localizations were detected with magnetic resonance imaging. Examination of superficial sensation and proprioception was performed in all patients. Differences in sensory function response to application of cotton wool (light touch), a cold metal object (cold sensation), and a size 6.65 (sharpness) Semmes Weinstein filament were recorded. Proprioception was tested on thumbs and big toes. The tactile detection threshold was determined using Semmes Weinstein filaments (Touch-Test Hand Kit, North Coast Medical, Inc., USA) ${ }^{6}$ ). Spasticity was assessed using the Modifiye Aschworth scale ${ }^{12}$.

The patients were diagnosed with CPSP based on the diagnostic criteria of Klit et al ${ }^{1)}$. Duration, localization, characteristics, and rhythm of pain and the relationship between activity and treatment methods were recorded in patients with CPSP. Patients were asked to rate their average pain intensity during the past week on a Visual Analogue Scale (VAS), with $0=$ "no pain" and $10=$ "pain as bad as could be"13). The Leeds Assessment of Neuropathic Symptoms and Signs (LANSS) scale was used to discriminate between neuropathic and non-neuropathic pain ${ }^{13}$ ). Scores of 12 or higher (out of a total of 24) were considered to indicate neuropathic pain. Pain type was classified into four categories according to location, description, and apparent origin as described elsewhere. CPSP is a neuropathic pain resulting from dysfunction of the central nervous system. It is characterized by pain and sensory abnormalities in the body parts corresponding to the brain territory injured by the cerebrovascular lesion. Pharmacologic agents used for neuropathic pain in CPSP. Adaptation of the LANSS scale to the Turkish patient population was carried out by Yücel et al ${ }^{14)}$. The VAS and LANSS scales were used only in Group I.

Functional outcomes, QoL, and depressive symptoms were assessed using the Turkish versions of the Functional Independence Measurement (FIM), 36-Item Short-Form Health Survey quality of life scale (SF-36 QoLS), and Beck Depression Inventory (BDI), respectively ${ }^{15-17)}$. FIM consist 6 subtests (self-care, sphincter control, transfer, locomotion, communication, and social cognitive ability) with a maximum total score of 126 . The SF-36 QoLS measures 8 parameters as physical function, physical role limitations, pain, general health, energy/vitality, social function, mental status role, and mental health. ${ }^{18)}$ The subscales evaluate health with scores between 0 and 100 ( $0=$ "worst health status" and $100=$ "good health status"). The scores of two components, namely the physical and mental scores, were evaluated. BDI is a 21-item, self-report rating inventory that measures characteristic attitudes and symptoms of depression. Higher total scores indicate more severe depressive symptoms ${ }^{19)}$.

SPSS Statistics 16.0 (SPSS, Chicago, IL, USA) was used for statistical analyses. Descriptive statistics were applied in the analyses. The chi-square test was used to compare the categorical data of both groups. The Mann-Whitney test was applied to compare the continuous variables between two groups. Pearson correlation analysis and linear regression analysis were performed to identify the relationship between physical and mental scores of the SF-36 QoLS and LANSS score. The level of statistical significance was set at $\mathrm{p}<0.05$.

\section{RESULTS}

Characteristics of the groups are presented in Table 1. There were no significant differences between the groups except lesion localization. Pain-related features of the patients with stoke and CPSP are presented in Table 2. Accordingly, the most common localization of pain was on one side of the body (including face, upper and lower extremities). The most common characteristics of pain were burning, pricking, throbbing, diminishing with activity, and increasing at night. Most patients were taking analgesics andor an anticonvulsant for treatment. Hyperalgesia and allodinia were observed in $87.5 \%$ of these patients. Sensorial deficit was observed 19 of 24 patients with CPSP (79\%). In our sample of patients, $45.8 \%$ presented with light touch, $8.3 \%$ with light touch with proprioception, and $12.5 \%$ with light touch with temperature sensation deficits.

Comparisons of clinical variables in both groups are presented in Table 3. There were no significant differences in FIM (motor, cognitive, total) and BDI scores. Some of the SF-36 domains (physical role limitations, pain, and physical scores) in Group II were significantly higher than in Group I $(\mathrm{p}<0.005)$. Moderate negative correlation was found between the LANSS scores and physical score $(\mathrm{p}=0.0001, \mathrm{r}=-0.619)$. Linear regretion revealed that a unit increase in LANNS score led to a 0.679 decrease in physical score $[\mathrm{r}=0.639 \mathrm{f}(1,61)=42.15$ beta $=-0.679](\mathrm{p}=0.0001)$ and a 0.387 decrease in mental score $[\mathrm{r}=0.214$ $\mathrm{f}(1,61)=2.91$ beta $=-0.387](\mathrm{p}=0.093)$. 
Table 1. Characteristics of groups

\begin{tabular}{|c|c|c|}
\hline & $\begin{array}{c}\text { Group I } \\
n=24\end{array}$ & $\begin{array}{c}\text { Group II } \\
n=24\end{array}$ \\
\hline \multicolumn{3}{|l|}{ Gender } \\
\hline Female/Male & $15 / 9$ & $11 / 13$ \\
\hline \multicolumn{3}{|l|}{ Marital status } \\
\hline Married/Widowed & $20 / 4$ & $22 / 2$ \\
\hline \multicolumn{3}{|l|}{ Educational Level } \\
\hline Illiterate/Primary school/ High school & $4 / 12 / 8$ & $9 / 10 / 5$ \\
\hline Duration of stroke (months) & $6(18 / 2)$ & $4(6 / 3)$ \\
\hline \multicolumn{3}{|l|}{ Type of stroke } \\
\hline Ischemic/Hemoragic & $20 / 4$ & $18 / 6$ \\
\hline \multicolumn{3}{|l|}{ Side of stroke } \\
\hline Right/Left & $16 / 8$ & $15 / 9$ \\
\hline \multicolumn{3}{|l|}{ Dominant hemisphere } \\
\hline Right/Left & $22 / 2$ & $21 / 3$ \\
\hline Number of comorbidities & $1(3 / 1)$ & $1(2 / 0)$ \\
\hline \multicolumn{3}{|l|}{ Localization of lesion } \\
\hline Thalamus/Extrathalamus/Brain stem** & $14 / 7 / 3$ & $1 / 22 / 1$ \\
\hline \multicolumn{3}{|l|}{ Sensorial deficit } \\
\hline Present/Absent & $11 / 13$ & $19 / 5$ \\
\hline \multicolumn{3}{|l|}{ Spasticity } \\
\hline Present/Absent & $13 / 11$ & $16 / 8$ \\
\hline
\end{tabular}

Table 2. Pain-related features in patients with central post-stroke pain $(\mathrm{n}=24)$

\begin{tabular}{lc}
\hline & mean \pm SD, $\mathrm{n}(\%)$, median $(\mathrm{max} / \mathrm{min})$ \\
\hline Duration of pain (months) & $2.3 \pm 0.9(1-4)$ \\
Localization of pain & \\
Extremity/Face and extremity/Body and extremity/Face, body and extremity & $9(37.5) / 5(20.8) / 1(4.2) / 9(37.5)$ \\
Characteristics of pain & $1(4.2)$ \\
Burning & $1(4.2)$ \\
Pricking & $14(58.3)$ \\
Burning and pricking & $1(4.2)$ \\
Burning and lacerating & $2(8.3)$ \\
Burning, pricking and throbbing & $3(12.5)$ \\
Burning, aching and throbbing & $2(8.3)$ \\
Aching and lacerating & $10(41.6) / 8(58.3)$ \\
Relationship with activity & \\
Decreasing/Stable & $6(25) / 2(8.3) / 16(66.6)$ \\
Rhythm of pain & \\
Morning/Evening /Night & $13(54.6)$ \\
Treatment & $5(30.0)$ \\
Only anticonvulsant & $4(16.8)$ \\
Anticonvulsant plus NSAID & $2(8.4)$ \\
Anticonvulsant plus opioids & $7.5 \pm 1.0$ \\
Anticonvulsant plus NSAID plus opioids & $9.5(18 / 0)$ \\
VAS scores & LANSS scores
\end{tabular}

CPSP: central poststroke pain, NSAID: non-steroidal anti-inflammatory drugs, VAS: Visual Analog Scale, LANSS: Leeds Assessment of Neuropathic Symptoms and Signs, n: number. Data are given as mean \pm standard deviation, ratio and median (max/ $\min )$ 
Table 3. Comparison of clinical variables in between groups

\begin{tabular}{lcc}
\hline & Group I & Group II \\
\hline FIM scale & & \\
Motor FIM & $59(80 / 41)$ & $61.5(89 / 26)$ \\
Cognitive FIM & $33(35 / 21)$ & $35(35 / 21)$ \\
Total FIM & $89.5(115 / 76)$ & $95.5(119 / 61)$ \\
SF-36QoLS & & \\
Physical function & $15.2(19.4 / 15.2)$ & $15.2(27.8 / 15.2)$ \\
Physical role limitations* & $28(56.2 / 28)$ & $28(28 / 28)$ \\
Pain & $33.2(46.5 / 19.9)$ & $49.4(62.7 / 11.6)$ \\
General health & $28.9(41.5 / 26.5)$ & $28.9(54.6 / 24.2)$ \\
Vitality & $37.2(46.7 / 25.4)$ & $38.4(53.8 / 28.4)$ \\
Social function & $30(46.3 / 13.7)$ & $24.6(46.3 / 19.1)$ \\
Mental status role & $23.7(55.3 / 23.7)$ & $23.7(55.3 / 23.7)$ \\
Mental health & $28.9(50.4 / 16.4)$ & $32.2(50.4 / 14.1)$ \\
Physical score** & $25(32.7 / 17.5)$ & $28.8(42.1 / 24.3)$ \\
Mental score & $30.7(51.4 / 21.6)$ & $33.2(59.7 / 17.9)$ \\
BDI scale & $18(32 / 1)$ & $14(25 / 9)$ \\
\hline CPSP: central poststroke pain, FIM: Functional Independence Measurement, SF-36 QoLS: Short-Form \\
36 Quality of Life Scale, BDI: Beck Depression Inventory. Data are given as median (max/min). ${ }^{*}$ p<0.05, \\
** $<$ < 0.01
\end{tabular}

\section{DISCUSSION}

Central poststroke pain may significantly affect functionality and negatively influence physical activity of patients with stroke but very few data on this topic are available ${ }^{5,8,20}$. Most commonly, CPSP develops within 3 to 6 months of stroke, although it may occur within a month after stroke ${ }^{16)}$. In our patients, pain onset occurred between 1 and 4 months after stroke. The presentation of CPSP is variable. Adjectives such as lacerating, aching, burning, freezing, and squeezing are commonly used by patients ${ }^{21)}$, as observed in our patients. Regarding the location of pain, hemisyndrome or lower limb involvement is frequently noted ${ }^{1}$, which is in agreement with the present study. Additionally, the severity of pain decreased with activity and increased at night in our patients. Some studies showed that the intensity of spontaneous pain fluctuated frequently and could be increased by internal or external stimuli (such as stress or cold) and alleviated by rest or distraction ${ }^{22}$.

Higher spasticity and sensory deficits are usually related to more severe neuropathic pain ${ }^{5)}$. The association between spasticity and neuropathic pain suggests that the role of spasticity in the pathogenesis of poststroke pain should be reevaluated and that the possibility of developing abnormal brain plasticity should be considered. In contrast we found that CPSP was not related to sensory impairment and spasticity.

Central poststroke pain was attributed to a thalamic lesion in the past, but it is known to also be associated with extrathalamic lesions ${ }^{3,21)}$. Localization in the thalamus was more common in our patients with CPSP. In some studies, higher pain intensities have been reported when the lesions were located in the brainstem or thalamus than in other areas; however, in another study, the symptoms and severity of CPSP in thalamic versus extrathalamic stroke did not differ ${ }^{21,23)}$. Further studies with a large number of stroke patients with CPSP are needed to clarify this topic.

Central poststroke pain is challenging to treat, and often involves a trial-and-error process with multiple different therapies $^{21)}$. The majority of our patients were treated with analgesic/anti-inflammatory drugs and an anticonvulsant, in agreement with study by Zorowitz et al. In their study, the most frequently prescribed pain medications for CPSP were analgesics, acetaminophen and tramadol, followed by an anticonvulsant ${ }^{24)}$.

In our study, no differences between the groups in FIM indicated that CPSP did not affect the functional outcomes. One previous study stated that CPSP was not a disturbing symptom for patients and did not limit daily activities ${ }^{25)}$. This was the expected result; CPSP affected the physical function, pain, and physical score components of the SF-36 QoLS poorly, but the other components of the SF-36 QoLS were not affected in our patients. Previous studies showed that CPSP affected not only physical functions but also mental functions poorly ${ }^{26-28)}$. We thought that this difference was due to the protocol of our study which was a controlled study. Additionally, CPSP did not affect the depression and mental scores of the SF-36 QoLS in our study and these results were in agreement with previous studies. In contrast, Appelros detected a strong relationship between poststroke pain and depression ${ }^{29}$. Widar et al. stated that poststroke pain was associated with sleep disturbances, fatigue, lack of fitness, mood lability and stress ${ }^{30}$. Further controlled studies with a large number of stroke patients with CPSP are needed to clarify the effect of CPSP on the state of mind related to QoL. 
In conclusion, to best of our knowledge, this is the first controlled study indicatin that CPSP has a negative impact on the physical subscale score of the SF-36 QoLS in patients with stroke. We propose that CPSP should be treated in a multidisciplinary setting to improve QoL.

\section{REFERENCES}

1) Klit H, Finnerup NB, Jensen TS: Central post-stroke pain: clinical characteristics, pathophysiology, and management. Lancet Neurol, 2009, 8: 857-868. [Medline] [CrossRef]

2) Klit H, Finnerup NB, Andersen G, et al.: Central poststroke pain: a population-based study. Pain, 2011, 152: 818-824. [Medline] [CrossRef]

3) Lee IH, Kim YN, Son CS, et al.: Clinical aspects of screening test tools for central neuropathic pain in patients with thalamic stroke. J Phys Ther Sci, 2011, 23: 749-752. [CrossRef]

4) Hong E: Comparison of quality of life according to community walking in stroke patients. J Phys Ther Sci, 2015, 27: 2391-2393. [Medline] [CrossRef]

5) Aprile IG, Briani C, Pazzaglia C, et al.: Pain in stroke patients: characteristics and impact on the rehabilitation treatment. A multicenter cross-sectional study. Eur J Phys Rehabil Med, 2015, [Epub ahead of print]. [Medline]

6) Vincent-Onabajo GO, Hamzat TK, Owolabi MO: Consistent determinants of health-related quality of life in the first 12 months after stroke: a prospective study in Nigeria. Top Stroke Rehabil, 2015, 22: 127-133. [Medline] [CrossRef]

7) Tang WK, Grace Lau C, Mok V, et al.: Insomnia and health-related quality of life in stroke. Top Stroke Rehabil, 2015, 22: 201-207. [Medline] [CrossRef]

8) Kumar G, Soni CR: Central post-stroke pain: current evidence. J Neurol Sci, 2009, 284: 10-17. [Medline] [CrossRef]

9) Kim KJ, Heo M, Chun IA, et al. PhDc: The relationship between stroke and quality of life in Korean adults: based on the 2010 Korean community health survey. J Phys Ther Sci, 2015, 27: 309-312. [Medline] [CrossRef]

10) Kim JH, Park EY: Mediating effect of self-control in relation to depression, stress, and activities of daily living in community residents with stroke. J Phys Ther Sci, 2015, 27: 2585-2589. [Medline] [CrossRef]

11) Yağci N, Duymaz T, Cavlak U: How does pain localization affect physical functioning, emotional status and independency in older adults with chronic musculoskeletal pain? J Phys Ther Sci, 2014, 26: 1189-1192. [Medline] [CrossRef]

12) Naghdi S, Ebrahimi I, Asgari A, et al.: A preliminary study into the criterion validity of the Modified Modified Ashworth Scale using the new measure of the alpha motoneuron excitability in spastic hemiplegia. Electromyogr Clin Neurophysiol, 2007, 47: 187-192. [Medline]

13) Frank AJ, Moll JM, Hort JF: A comparison of three ways of measuring pain. Rheumatol Rehabil, 1982, 21: $211-217$. [Medline] [CrossRef]

14) Yücel A, Şenocak M, Kocasoy Orhan E, et al.: Results of the Leeds assessment of neuropathic symptoms and signs pain scale in Turkey: a validation study. J Pain, 2004, 5: 427-432. [Medline] [CrossRef]

15) Küçükdeveci AA, Yavuzer G, Elhan AH, et al.: Adaptation of the functional independence measure for use in Turkey. Clin Rehabil, 2001, 15: 311-319. [Medline] [CrossRef]

16) Koçyiğit H, Aydemir Ö, Fişek G, et al.: The reliability and validity of Turkish version of Short form 36 (SF 36). J Drug Treat, 1995, 12: 102-106.

17) Hisli N: A study on the validity of the Beck Depression Inventory. J Psychol, 1988, 6: 118-122.

18) Ware JE Jr: The status of health assessment 1994. Annu Rev Public Health, 1995, 16: 327-354. [Medline] [CrossRef]

19) Beck AT, Ward CH, Mendelson M, et al.: An inventory for measuring depression. Arch Gen Psychiatry, 1961, 4: 561-571. [Medline] [CrossRef]

20) Widar M, Ahlström G, Ek AC: Health-related quality of life in persons with long-term pain after a stroke. J Clin Nurs, 2004, 13: 497-505. [Medline] [CrossRef]

21) Harrison RA, Field TS: Post stroke pain: identification, assessment, and therapy. Cerebrovasc Dis, 2015, 39: 190-201. [Medline] [CrossRef]

22) Leijon G, Boivie J, Johansson I: Central post-stroke pain—neurological symptoms and pain characteristics. Pain, 1989, 36: 13-25. [Medline] [CrossRef]

23) Misra UK, Kalita J, Kumar B: A study of clinical, magnetic resonance imaging, and somatosensory-evoked potential in central post-stroke pain. J Pain, 2008, 9: 1116-1122. [Medline] [CrossRef] 
24) Zorowitz RD, Smout RJ, Gassaway JA, et al.: Usage of pain medications during stroke rehabilitation: the Post-Stroke Rehabilitation Outcomes Project (PSROP). Top Stroke Rehabil, 2005, 12: 37-49. [Medline] [CrossRef]

25) Yanagida H, Arakawa K, Sakai K, et al.: Intensity of central pain: analysis of pain scores in 18 patients. Pain Pract, 2003, 3: 117-119. [Medline] [CrossRef]

26) Raffaeli W, Minella CE, Magnani F, et al.: Population-based study of central post-stroke pain in Rimini district, Italy. J Pain Res, 2013, 6: 705-711. [Medline]

27) Wolfe CD, Crichton SL, Heuschmann PU, et al.: Estimates of outcomes up to ten years after stroke: analysis from the prospective South London Stroke Register. PLoS Med, 2011, 8: e1001033. [Medline] [CrossRef]

28) Jönsson AC, Lindgren I, Hallström B, et al.: Determinants of quality of life in stroke survivors and their informal caregivers. Stroke, 2005, 36: 803-808. [Medline] [CrossRef]

29) Appelros P: Prevalence and predictors of pain and fatigue after stroke: a population-based study. Int J Rehabil Res, 2006, 29: 329-333. [Medline] [CrossRef]

30) Widar M, Ek AC, Ahlström G: Coping with long-term pain after a stroke. J Pain Symptom Manage, 2004, $27: 215-225$. [Medline] [CrossRef] 